\title{
Exacerbation of pulmonary fibrosis following single lung transplantation
}

\author{
Dawei Yang ${ }^{1,2}$, Jennifer M Wilson MD ${ }^{1,3}$, Chunxue Bai MD PhD FCCP², John Yee MD $^{3,4}$, \\ Pearce G Wilcox MD ${ }^{1}$, Nasreen Khalil MD¹, Robert D Levy MD FCCP1,3
}

\author{
D Yang, JM Wilson, C Bai, et al. Exacerbation of pulmonary fibrosis \\ following single lung transplantation. Can Respir J 2012;19(1): \\ e3-e4.
}

Acute exacerbations of interstitial lung disease present as clinical deteriorations, with progressive hypoxemia and parenchymal consolidation not related to infection, heart failure or thromboembolic disease. Following single lung transplantation, patients receive maintenance immunosuppression, which could mitigate the development of acute exacerbations in the native lung. A 66-year-old man with fibrotic, nonspecific interstitial pneumonitis presented with fever, hypoxemia and parenchymal consolidation limited to the native lung four years after single lung transplantation. Investigations were negative for infection, heart failure and thromboembolic disease. The patient worsened over the course of one week despite broad-spectrum antimicrobial therapy, but subsequently improved promptly with augmentation of prednisone dosed to $50 \mathrm{mg}$ daily and addition of $\mathrm{N}$-acetylcysteine. Hence, the patient fulfilled the criteria for a diagnosis of an acute exacerbation of pulmonary fibrosis in his native lung. Clinicians should consider acute exacerbation of parenchymal lung disease of the native lung in the differential diagnosis of progressive respiratory deterioration following single lung transplantation for pulmonary fibrosis.

Key Words: Acute exacerbation; Lung transplantation; Nonspecific interstitial pneumonitis; Pulmonary fibrosis

$\Delta$ cute exacerbations of interstitial lung disease present with proIgressive hypoxemia and parenchymal opacification not related to infection, heart failure or thromboembolic disease. Following single lung transplantation, patients receive maintenance immunosuppression, which could prevent the development of acute exacerbations in the native lung.

\section{CASE PRESENTATION}

A 66-year-old man presented in April 2010 with three days of fever, cough, shortness of breath and malaise. He had undergone a right single lung transplant in 2006 for fibrotic nonspecific interstitial pneumonia (fNSIP). He was on maintenance immunosuppression with tacrolimus $0.5 \mathrm{mg}$ twice daily, mycophenolate $1.5 \mathrm{~g}$ twice daily and prednisone $5 \mathrm{mg}$ daily. The post-transplant course was complicated by acute rejection in 2006, which was treated with pulse steroids. Two years before admission, he developed grade 3 bronchiolitis obliterans syndrome (1). The patient had gastroesophageal reflux, which was treated with proton pump inhibitors and laparoscopic fundoplication one year before presentation.

The patient had no recent sick contacts, no new medications, no travel within the previous year and no identifiable environmental exposures of concern. A chest radiograph showed patchy airspace opacification in the lower lung zone of the left (native) lung with stable (unchanged) findings in the right transplanted lung (Figure 1B). His temperature was $38.4^{\circ} \mathrm{C}$, with a respiratory rate of 24 breaths $/ \mathrm{min}$

\section{L'exacerbation d'une fibrose pulmonaire après la greffe d'un seul poumon}

Les exacerbations aiguës des maladies pulmonaires interstitielles se présentent sous forme de détériorations cliniques, accompagnées d'une hypoxémie évolutive et d'une condensation parenchymateuse non liée à une infection, à une insuffisance cardiaque ou à une maladie thromboembolique. Après la greffe d'un seul poumon, les patients reçoivent une immunosuppression d'entretien, qui pourrait atténuer l'apparition d'exacerbations aiguës du poumon natif. Un homme de 66 ans ayant une pneumonite interstitielle fibreuse non spécifique a consulté à cause de fièvre, d'hypoxémie et de condensation parenchymateuse limitée au poumon natif quatre ans après la greffe d'un seul poumon. Les examens n'ont pas révélé d'infection, d'insuffisance cardiaque et de maladie thromboembolique. L'état du patient s'est aggravé en l'espace d'une semaine malgré une antibiothérapie à large spectre, mais s'est ensuite amélioré rapidement après l'augmentation de la dose de prednisoneà $50 \mathrm{mg}$ par jour et l'ajout de $\mathrm{N}$-acétylcystéine. Ainsi, le patient a respecté les critères diagnostiques d'exacerbation aiguë de la fibrose pulmonaire dans le poumon natif. Les cliniciens devraient envisager une exacerbation aiguë de la maladie pulmonaire parenchymateuse du poumon natif dans le diagnostic différentiel de la détérioration respiratoire évolutive après la greffe d'un poumon en traitement d'une fibrose pulmonaire.

and an oxygen saturation of $90 \%$ on room air. On chest examination, there were diminished breath sounds over the right transplanted lung and late-inspiratory crackles over the left lung base without bronchial breath sounds. The patient was admitted to hospital with presumed pneumonia and was started on intravenous meropenem, vancomycin and ganciclovir pending culture results.

Arterial blood gas results revealed a $\mathrm{PaO}_{2}$ of $90 \mathrm{mmHg}$ on $3 \mathrm{~L} / \mathrm{min}$ by nasal prongs, his white blood cell count was $7.610^{9} / \mathrm{L}$, and his trough tacrolimus level was therapeutic. A high-resolution computed tomography (HRCT) scan of his chest showed diffuse ground-glass opacification throughout the left native lung along with stable findings of NSIP (Figure 1B), and findings in the right lung allograft were unchanged when compared with a surveillance HRCT performed three months earlier (Figure 1A). Sputum cultures were negative for bacterial, fungal and mycobacterial pathogens. Bronchoscopy was performed, but transbronchial biopsies were not taken due to the patient's compromised status. Minimal clear secretions were observed bilaterally. Bronchoalveolar lavage and bronchoscopic brush cultures were negative for bacterial, fungal, viral, and mycobacterial pathogens as well as for pneumocystis. There was no evidence of heart failure on transthoracic echocardiogram and no acute or chronic pulmonary embolism on contrast-enhanced computed tomography.

The fever and hypoxemia did not improve during the following week, and chest imaging showed progressive opacification of the left native lung (Figure 1C). In view of the negative cultures and

${ }^{1}$ Division of Respiratory Medicine, Department of Medicine, University of British Columbia, Vancouver, British Columbia; ${ }^{2}$ Department of

Pulmonary Medicine, Zhongshan Hospital, Fudan University, Shanghai, China; ${ }^{3}$ British Columbia Transplant; ${ }^{4}$ Division of Thoracic Surgery,

Department of Surgery, University of British Columbia, Vancouver, British Columbia

Correspondence: Dr Robert D Levy, Division of Respiratory Medicine, Department of Medicine, University of British Columbia, 8B-1081, Burrard Street, Vancouver, British Columbia V6Z 1Y6. Telephone 604-806-9151, fax 604-806-8722, e-mail robert.levy@vch.ca 

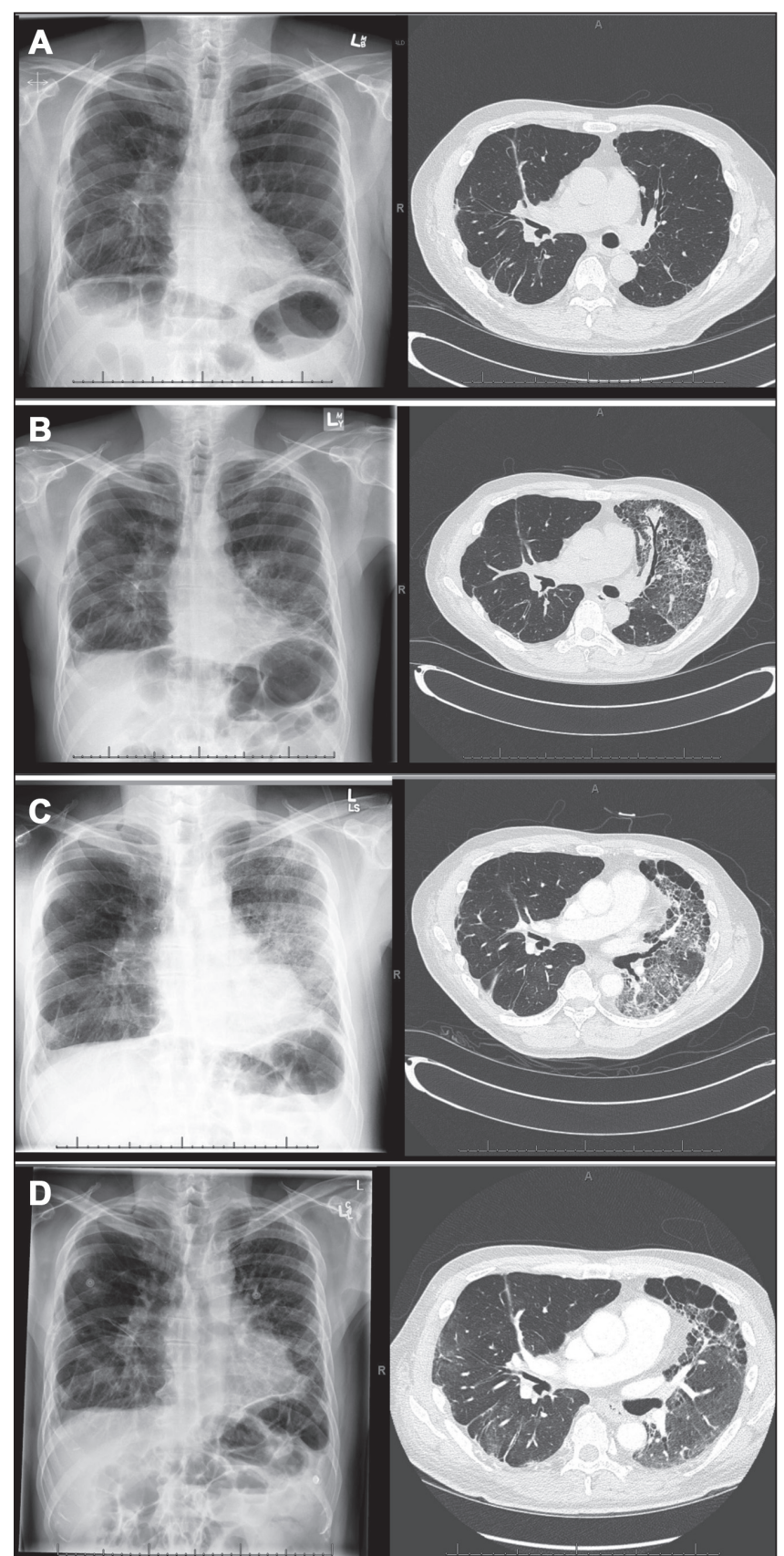

Figure 1) Chest radiographs and high-resolution computed tomography studies showing worsening diffuse ground-glass changes in the native left lung superimposed on stable findings of fibrotic nonspecific interstitial pneumonia. The right lung allograft was unaffected. A Baseline three months prehospitalization. B Hospital admission. C Day 10, before prednisone pulse $+N$-acetylcysteine. The left lung opacification improved following institution of pulse prednisone and $N$-acetylcysteine $(1 D$, day 60 , following 45 days augmented prednisone $+N$-acetylcysteine parenchymal consolidation restricted to the native lung, a tentative diagnosis of acute exacerbation of ANSIP was made. Prednisone $1 \mathrm{mg} / \mathrm{kg}$ orally daily and $\mathrm{N}$-acetylcysteine $600 \mathrm{mg}$ orally three times/day were initiated. Over the next two weeks, the patient's condition gradually improved and the chest radiograph returned to baseline (Figure 1D). He was discharged on prednisone, which was tapered gradually over the following four months to $20 \mathrm{mg}$ daily. On discharge, he required oxygen at $4 \mathrm{~L} / \mathrm{min}$ to $6 \mathrm{~L} / \mathrm{min}$ by nasal prongs and, at three months postdischarge, his oxygen saturation was $93 \%$ on room air, but he continued to require supplemental oxygen with exercise.

\section{DISCUSSION}

This patient presented with fever, hypoxemia and parenchymal opacification exclusively affecting the native lung, with this unilaterality making infection and aspiration unlikely. He did not respond to broadspectrum antibiotics, respiratory cultures were negative for pathogens, and he only improved once high dose prednisone and $\mathrm{N}$-acetylcysteine (2) were initiated. Despite the absence of pathological confirmation, he fulfilled the criteria for an acute exacerbation of NSIP as described by Akira et al (3) including: subjective worsening of dyspnea within the previous month; new ground-glass opacities or consolidation on chest radiograph or HRCT; hypoxemia with decline $\geq 10 \mathrm{mmHg}$ in $\mathrm{PaO}_{2}$ from the previous level; no evidence for infection with negative respiratory cultures and serological test results for respiratory pathogens; and no clinical evidence of pulmonary embolism, congestive heart failure, or pneumothorax as a cause of acute worsening.

Acute exacerbations have been reported in patients with idiopathic pulmonary fibrosis (4), hypersensitivity pneumonitis (5), and NSIP with or without collagen vascular disease (6). The outcome of acute exacerbations in NSIP appears to be better than that in idiopathic pulmonary fibrosis (6).

The present case highlights that acute exacerbations can occur in the native lung even in the presence of the modest levels of immunosuppression routinely provided for maintenance of lung allograft integrity. Clinicians should consider the possibility of an acute exacerbation of underlying pulmonary fibrosis in the differential diagnosis of progressive parenchymal opacification isolated to the native lung following single lung transplantation.

ACKNOWLEDGEMENTS: None of the authors had potential conflicts related to the topic of this article.

\section{REFERENCES}

1. Estenne M, Maurer JR, Boehler A, et al. Bronchiolitis obliterans syndrome 2001: An update of the diagnostic criteria.

J Heart Lung Transplant 2002;21:297-310.

2. Demedts M, Behr J, Buhl R, et al. High-dose acetylcysteine in idiopathic pulmonary fibrosis. N Engl J Med 2005;353:2229-42.

3. Akira M, Hamada H, Sakatani M, et al. CT findings during phase of accelerated deterioration in patients with idiopathic pulmonary fibrosis. Am J Roentgenol 1997;168:79-83.

4. Collard HR, Moore BB, Flaherty KR, et al. Acute exacerbations of idiopathic pulmonary fibrosis. Am J Respir Crit Care Med 2007;176:636-43.

5. Olson AL, Huie TJ, Groshong SD, et al. Acute exacerbations of fibrotic hypersensitivity pneumonitis. Chest 2008;134:844-50.

6. Park IN, Kim DS, Shim TS, et al. Acute exacerbation of interstitial pneumonia other than idiopathic pulmonary fibrosis. Chest 2007;132:214-20. 


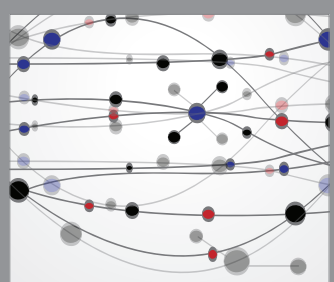

The Scientific World Journal
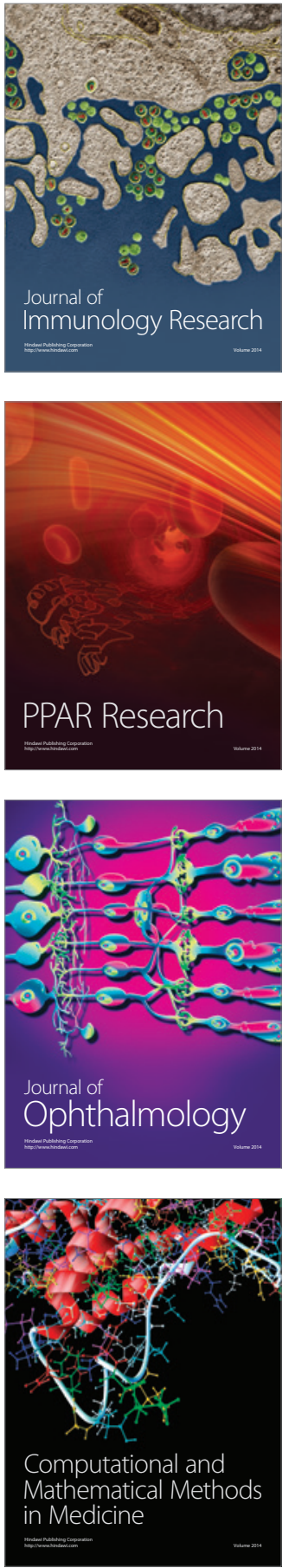

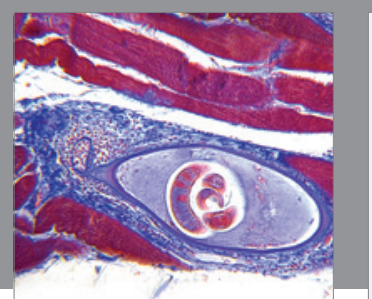

Gastroenterology Research and Practice

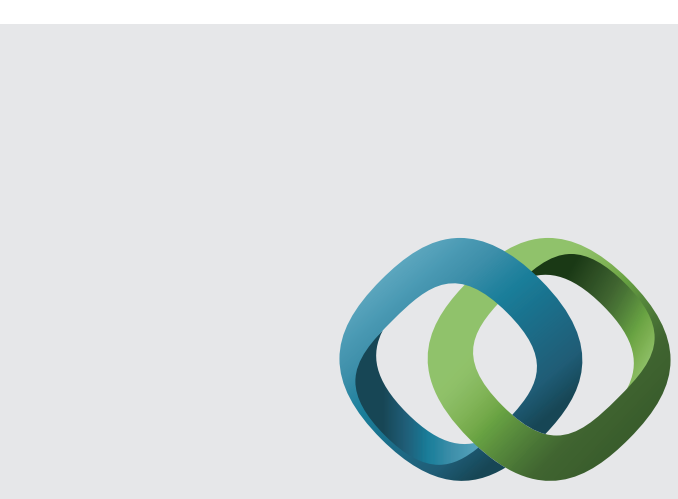

\section{Hindawi}

Submit your manuscripts at

http://www.hindawi.com
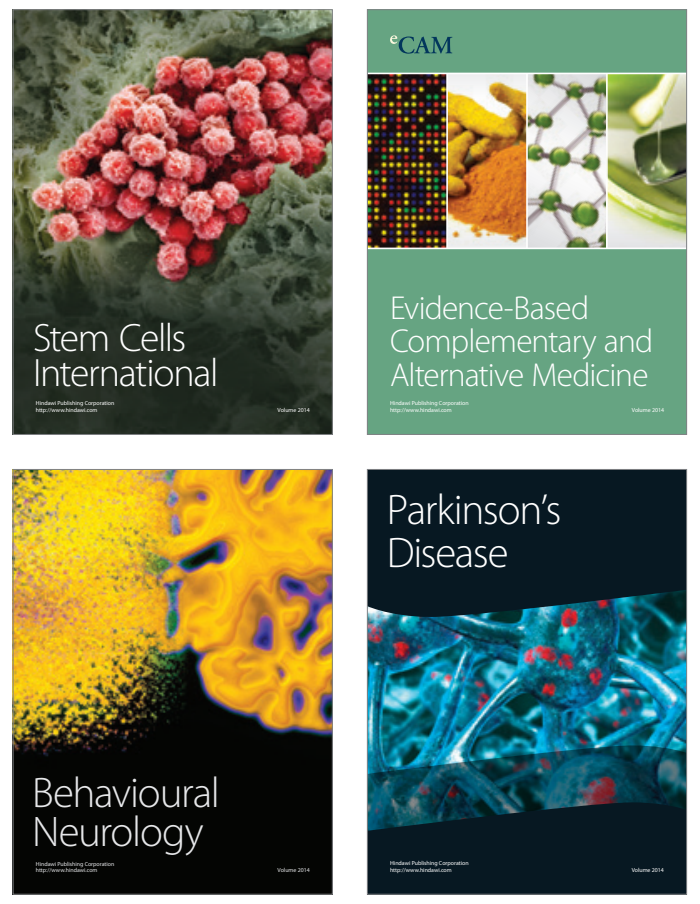
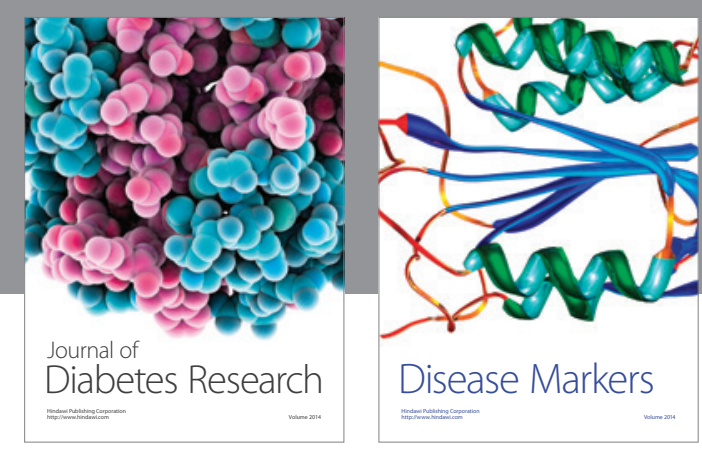

Disease Markers
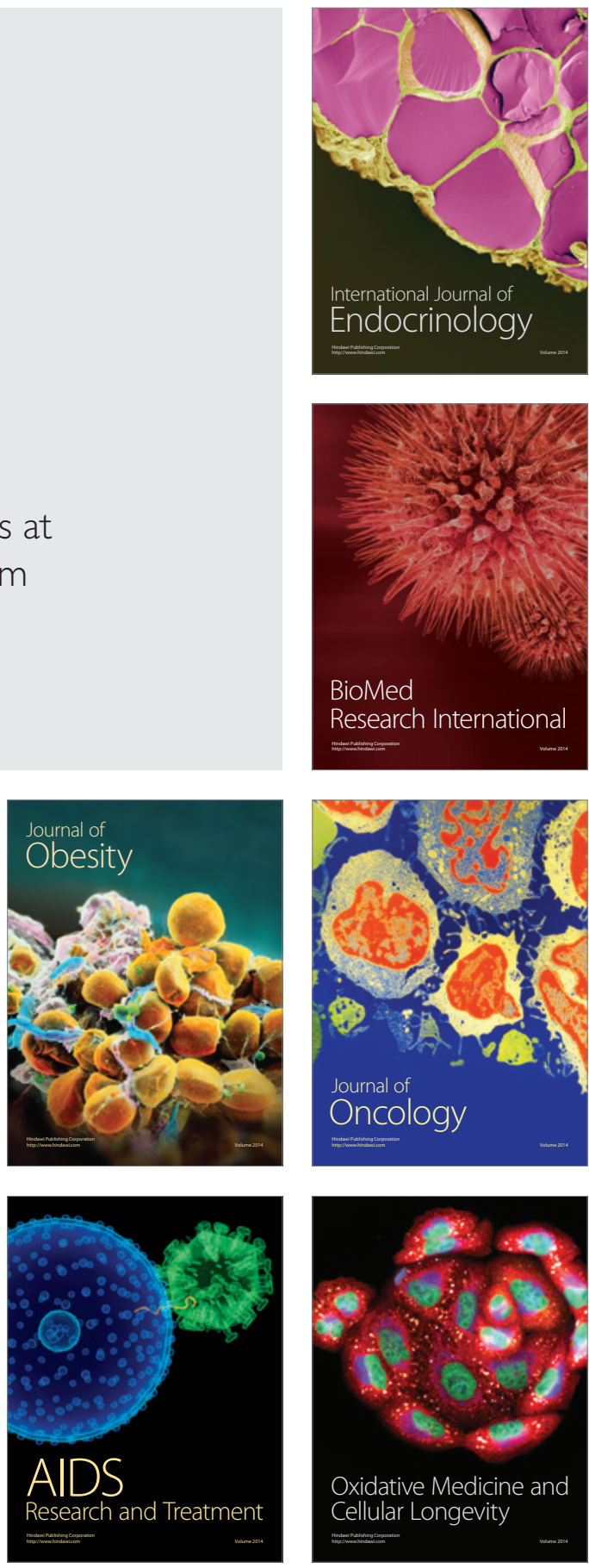